\title{
COLLABORATIVE SHARING-TASKS LEARNING FOR EARLY CHILDHOOD EDUCATION
}

\author{
Rosita Wondal, Farida Samad, Sasmayunita \\ Faculty of Teacher Training and Education, Khairun University, Indonesia \\ Jalan Bandara Baabullah, Kel. Akehuda, Ternate, North Moluccas, Indonesia \\ Corresponding Author: mrsasmayunita@yahoo.com
}

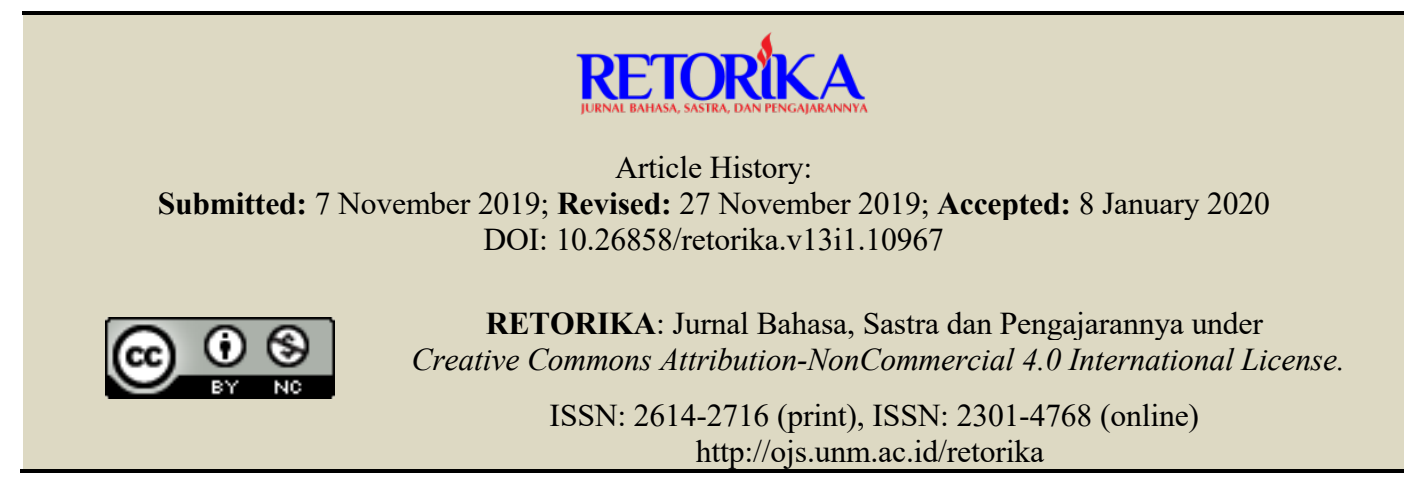

\begin{abstract}
This study aimed to describe the implementation of collaborative sharing-tasks learning on the 'Occupations' topic at Santo Yoseph Preschool Group B1 in Ternate. The students involved in this study were those registered in the 2018/2019 academic year. Data collection was performed using observation and documentation. In data analysis, Miles and Huberman interaction model was employed to describe the data qualitatively. The results of the study revealed that the implementation of collaborative sharing-tasks learning on "Occupations" implemented at Santo Yoseph Preschool Group B1 in Ternate was effective. Six groups of students were able to complete the tasks given by $76.92 \%$ through collaborative sharing-task learning. Therefore, it can be said that collaborative sharing-task learning can improve preschool students' ability in understanding materials on 'Occupations'.
\end{abstract}

Keywords: collaborative, sharing task

The $21^{\text {st }}$ century schools require the teachers to be innovative and adept at creating more fun and challenging learning activities in the classroom. Modern schools are formed based on the basic principle of simultaneous achievement in quality and equality. Learning is an interaction process between the instructor, students, and learning media that allows the students to actively develop multiple skills and paradigms. Interactive, inspiring, fun, and challenging learning activities can encourage students to achieve the desired competencies.

Greeberg (Isjoni, 2006) describes that effective learning helps children learn while play- ing, working, and living harmoniously with their environment. Early childhood education does not mean sending children to schools as soon as they are eligible. Instead, early childhood education provides learning for children so that they can develop optimally. Putting much burden in children by sending them to schools at an inappropriate age can disturb their attempt in fulfilling their developmental tasks.

In fact, classroom activities in Santo Yoseph Preschool Group B1 in Ternate are mostly dominated by discussion and lecturing methods. Group work was not run optimally; only one or two students were actively engaged in the dis- 
cussion. Collaborative learning, including authentic learning (which is in line with the characteristic of the materials) and relationships or interactions in learning (listen to each other) need to be developed for early childhood education.

Observations conducted at Santo Yoseph Preschool Group B1 in Ternate also showed that not all of the students were willing to help each other in completing the tasks given around the 'Occupations' topic. There were two main collaborative sharing tasks conducted in the classroom. The first one was to arrange letters into the correct word 'police officer' and the second one was to match picture with the word 'police car'.

During the learning process, the teacher seemed to be less active as the facilitator of learning. Occasionally, there were students who asked for the teacher's help to connect pictures and match patterns. In addition, different levels of ability (high, medium, and low) were also noticed in the classroom. Some students with high academic ability were willing to assist their peers in understanding and completing the tasks, while some others preferred to play games when they had understood the materials and rejoined the activities when the teacher explained new materials. Given these circumstances, therefore, it is necessary to optimize a collaborative learning process that can facilitate effective learning.

Collaborative sharing-tasks learning involves activities using individual tasks containing textbook materials that can be completed in a small group. Through sharing-tasks activities, all students despite their academic ability levels can be benefited. The assignment of problems in sharing-tasks activities will encourage the students to think more openly and comprehensively. The problem-solving activities motivate the students to be a confident problem-solver as well as prepare them to possess the ability to think scientifically, especially when faced with life challenges. According to Slamet Asari (2017), sharing-tasks activities are in line with the ZPD theory which states that students can work together with their peers through collaborative learning.

In sharing-tasks learning, textbook content is discussed to accommodate students' collaboration. Gustina, et al. (2018), through 'Sharing and Jumping Based Didactical Design In Col- laborative Learning on the topic of Covalent Bonding' revealed the existence of student-student collaboration and student-teacher collaboration in the classroom. Cahyani (2017) has concluded that sharing-tasks and jumping-tasks activities can minimize the barriers to learning and provide benefits for the low achievers.

The implementation of sharing-tasks activities in the classroom has been studied extensively on health students and students at higher levels of education (junior, senior, or higher education). Unlike the previous research, this study was focused on the application of sharing-tasks activities in early childhood education. This study specifically aimed to describe the implementation of collaborative sharing-tasks learning on the 'Occupations' topic at Santo Yoseph Preschool Group B1 in Ternate.

\section{METHOD}

The current study was conducted in AprilJune 2019. It employed a descriptive qualitative approach to describe the implementation of collaborative sharing-tasks learning on the 'Occupations' topic at Santo Yoseph Preschool Group B1 in Ternate. This study involved 13 children aged 5-6 years old who were registered in the preschool in the academic year of 2018/2019.

Data required for the analysis included documentation data obtained from Santo Yoseph Preschool in Ternate and observation data on the learning process conducted in the classroom. The researcher collected some documents related to the implementation of lesson study-based learning in the classroom. In addition, one model teacher and one homeroom teacher were invited as the main informants. Collaborative sharingtasks learning was implemented in Group B1 classroom which consisted of 13 students. 'Occupations' was selected as the topic to accompany the implementation of the collaborative learning process. Subjects of the study were determined based on the following considerations (purposive sampling): (a) the subjects were involved directly in the implementation of the collaborative learning activities, (b) the subjects understood the issue in question, were in charge of the required data, and were open for information reveal. The characteristics assigned to the subjects were aimed to assist information accuracy. 
According to the types of the data and source of data required for the analysis, data collection was performed using the following methods. Direct observation was conducted to investigate activities performed by the students during the implementation of the learning design as well as to obtain a clear description of "sha ring" among the participants. Observed indicators are provided in Table 1.

Tabel 1. Indicators and Activities of Colloborative Learning Tasks

\begin{tabular}{|c|c|c|c|}
\hline & \multicolumn{3}{|c|}{ Sharing Tasks } \\
\hline Indicator & $\begin{array}{l}\text { Explain a } \\
\text { relationship }\end{array}$ & $\begin{array}{l}\text { Explain a } \\
\text { causal rela- } \\
\text { tionship }\end{array}$ & $\begin{array}{l}\text { Describe a } \\
\text { picture }\end{array}$ \\
\hline \multirow[t]{2}{*}{ Activity } & \multicolumn{3}{|c|}{$\begin{array}{l}\text { Arrange letters into the correct word } \\
\text { "police officer" }\end{array}$} \\
\hline & \multicolumn{3}{|c|}{$\begin{array}{l}\text { Match pictures with the correct word } \\
\text { "police car" }\end{array}$} \\
\hline
\end{tabular}

Table 2. Criteria for Assessing Collaborative Sharing-Tasks Learning Activities

\begin{tabular}{crl}
\hline Criteria & Scores & \multicolumn{1}{c}{ Interpretation } \\
\hline BSB & $>75 \leq 100$ & $\begin{array}{l}\text { Children are able to disco- } \\
\text { ver knowledge/ perform } \\
\text { activities independently } \\
\text { and help other children. }\end{array}$ \\
BSH & $>50 \leq 75$ & $\begin{array}{l}\text { Children are able to dis- } \\
\text { cover knowledge/ perform } \\
\text { activities independently }\end{array}$ \\
MB & $>25 \leq 50$ & $\begin{array}{l}\text { Children are able to dis- } \\
\text { cover knowledge/ perform } \\
\text { activities independently, } \\
\text { but occasionally ask for } \\
\text { the teacher's help. } \\
\text { Children are not able to } \\
\text { discover knowledge/ per- } \\
\text { form activities inde- } \\
\text { pendently }\end{array}$ \\
\hline BM & $\leq 25$
\end{tabular}

Documents were collected in the form of videos, learning resources, learning materials on the 'Occupations' topic, student worksheet, syllabus (Curriculum 2013), lesson plan, and assessment sheet that were related to the implementation of collaborative sharing-tasks learning activities at Santo Yoseph Preschool Group B1 in Ternate.

A qualitative approach was used to analyze the observation and documentation data.
Data analysis was performed using the following steps: (a) data reduction, data reduction was the process of selecting, collecting, simplifying, abstracting, and transforming data on the implementation of collaborative sharing-tasks learning activities at at Santo Yoseph Preschool Group B1 in Ternate. Data reduction was guided by the research objective. (b) Data display, in this qualitative study, the data were displayed in the form of brief description, chart, picture/ scheme or table designed to arrange understandable information. Data display contains arranged information that provides possibilities to make conclusions and take action. Data presented in this study were in the form of verbal information or words on the implementation of collaborative sharing-tasks learning activities at Santo Yoseph Preschool Group B1 in Ternate on the 'Occupations' topic.

Verification continued throughout the study. This activity was intended to verify the data and consider whether the conclusions to be drawn truly met the objectivity aspect. In carrying out this step, the researcher had to go through the following stages: (a) triangulation, at this stage, data obtained from the primary sources, documentation, and literature review were triangulated. If the triangulator could provide the same data to every question raised at the source of the data, the conclusions drawn became much stronger. (b) Member check, at this stage, the researcher went back to the field to check all the data obtained from observation and documentation. Data and conclusions of the analyses were shown to the subjects to be cross-checked. The main conclusions of this study were drawn after the researcher's analyses were accepted and approved by the cross-check members.

\section{FINDINGS AND DISCUSSION}

\section{Findings}

Observation results related to the stages of lesson study used to clarify the implementation of sharing-tasks activities on the 'Occupations' topic are presented as follows.

\section{Plan}

The initial stage of preparation began with identifying the problem and alternative solutions to the problem that emerged among the students 
in Santo Yoseph Preschool Group B1. Based on experience, children normally find it difficult to sort words. 'Plan' stage was conducted on Tuesday, 4 February 2019 to discuss learning tools that were going to be used in the classroom, including lesson plans, learning media, learning materials, assessment sheet, and student worksheet containing two tasks (arranging letters into the correct word 'police officer' and matching pictures with the correct word 'police car'). This meeting was attended by a model teacher, the principal and four teachers from Santo Yoseph preschool as well as an observer team assigned to conduct the research. The students were divided into groups. Each group was required to perform 2-3 different activities in one meeting. The designated model teacher for open class and lesson design was Ms.

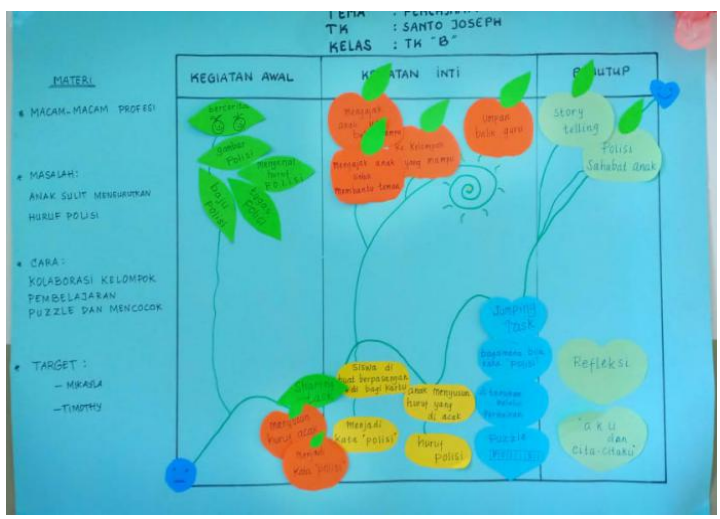

Figure 1. Lesson Design (LD) for Preschool Group B1 Students on the 'Occupations' Topic

Do

This stage was conducted after all of the learning tools were ready to use. 'Do' stage was performed by the model teacher in the Group B1 classroom. The main activities conducted in the classroom were adjusted to the lesson plans that had been designed previously by the team of observers and the model teacher. Before entering the classroom, the students lined up, prayed together, sang the 'see the police man' song, recited the 'policeman' poem, chanted the 'new spirit of applause' while running and jumping excitedly. Pre-teaching involved interacting with the students about occupations. The teacher then asked the students to mention the duties of a police officer or a traffic police. After that, the teacher delivered the learning objectives for that day which were to arrange scrambled letters into the 'police officer' word and to tell the 'police is the children's best friend'. Before the students were divided into groups, the teacher explained the types of activities and tasks that had to be completed by the students in groups. The students were allowed to discuss in groups to complete the tasks provided on the sharing-tasks worksheet. During the main activity, the model teacher had the responsibility to encourage the emergence of group learning patterns. After the students finished their first task, they were required to proceed to the second task, that was to match pictures with the correct word 'police car'.

\section{See (Reflection)}

A reflection activity was performed at the end of the lesson. First of all, the model teacher was given the opportunity to express her opinions on the implementation of collaborative sharing-tasks learning in the Group B1 classroom. Then, the observers alternately conveyed their arguments and impressions on the learning process. This activity revealed that the learning design had been implemented appropriately from the beginning until the end. Positive suggestions and input were delivered based on lesson design and the learning design was revised based on the results of the observation. Collaborative sharingtasks learning on the 'Occupations' topic was assessed based on several aspects, including.

\section{The Implementation of Sharing-Tasks Ac- tivities in the Classroom}

\section{Explaining a Relationship}

Model teacher who acted as the homeroom teacher as well as the subject of the study first explained the theme given, 'Occupations'. The teacher asked children questions, for example 'what are the types of occupations? where do they work ?; and what do they do?'. There were children who responded to these questions, but there were also children who stayed quiet. After the teacher explained the theme and asked several questions related to the above theme, she picked up the letter cards and showed them to the students so that they could easily understand what was being learned. The available letter cards were adapted to the given sub-theme "Occupations". The model teacher then raised the 
letter cards one by one, pointed at the 'police officer' image on the blackboard and spelled the word 'police officer' which was written in a scrambled order under the picture. The teacher assigned the students into six groups consisting of 2 to 3 children including: Kimberlee and $\mathrm{Ki}-$ yomi, Jordan-Clara and Rafael, JonathanEmelin, Mikayla and Timothy, Kayleen and Siti and Katelina and Khenzo. The target students were Timothy and Kimberlee. Following is the class plan for group B1.

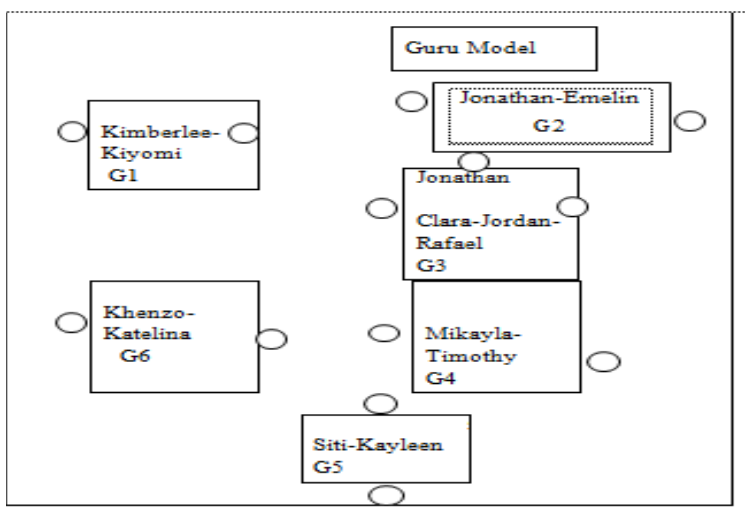

Figure 2. Class Plan

The teacher invited the students to collaborate with their group members to rearrange letters into the correct word 'police officer'. This activity was followed by matching pictures with the word 'police car'. Both sharing-tasks activities allowed the students to carry out group activities instructed by the model teacher. Mikayla and Timothy were very quick in completing the 'police' random sequencing activity without cheating on each other. Mikayla even took the initiative to help her friend in the group, Timothy, to complete the assignment. Likewise in the second task, Timothy, who lacked confidence, slowly matched pictures with the word 'police car' and his work looked surprisingly neat. During the activities, there was cooperation built between the two students. They were able to complete the tasks without asking for the teacher's help. Similarly, Kayleen was also able to complete her assignment before the time given. Kayleen is a very independent and active student. She was able to rearrange the letters into the correct word 'police officer' and match pictures with the 'police car' picture very swiftly. However, her final work was not very neat. On the other hand, it took quite a long time for Siti to complete the second task. Siti looked doubt- ful, preoccupied, and occasionally indulged in daydreams. However, the results of her work were quite neat compared to Kayleen's.

Other groups, such as Kiyomi and Kimberlee, failed to demonstrate collaborative attitudes in conducting their sharing-tasks activities. In fact, Kiyomi was often assisted by students from other groups namely Jonathan and Jordan, while Kimberlee seemed to have no difficulty at all in completing these two activities. Clara in her group, which consisted of Jordan and Rafael, was very thorough in rearranging the letters. Clara, Jordan, and Rafael were also able to complete their tasks quickly and help Kiyomi who was initially paired with Kimberlee. In contrast, Khenzo and Katelina's group was quite slow. In this group, Khenzo was the one who was very active in helping Katelina complete their sharing-tasks activities. To finish the tasks at the given time, Khenzo and Katelina had to receiev assistance from the teacher. Compared to Katelina's, Khen-zo's worksheet was more neatly done. Both Katelina and Khenzo seemed proud of their work that they had accomplished with the help of the teacher.

In addition, Emelin and Jonatan were able to work together in completing their sharing tasks. Emelin was often approached by Rafael when the matching picture activity was taking place. A noticeable quality found in this group was they shared tasks with each other.

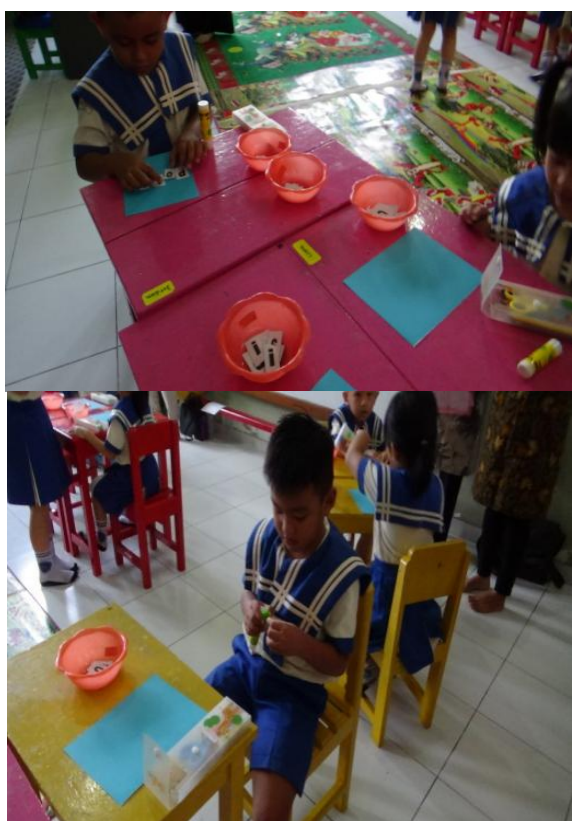

Figure 3. Sharing-tasks Activities in Jordan-Clara-Rafael group 
Thus, it can be concluded that some chidren have reached the standard in expressing the language assessed by the indicator of mentioning known letter symbols, for example there were students who were able to rearrange letters into the correct word 'police officer'. However, some others still needed more time and assistance from the teacher to arrange these random letters. There was a child who could arrange other random letters shown by the teacher, but he failed to recognize one letter so the model teacher had to remind him again. After the model teacher explained the theme and asked several questions to the students, she showed word cards as a learning medium used to help the children understand what was being learned.

\section{Explaining a Causal Relationship}

After the students completed the tasks, they were given the opportunity by the model teacher to discuss the word (police officer) displayed. Group members discussed with each other and worked together to determine the answer to the question posed by the teacher. They were very happy and enthusiastic to answer the teacher's questions about 'police officer'. The model teacher was also highly responsive to active students. Unfortunately, some students had not shown any participation or enthusiasm for learning in groups. They were shy and sometimes preoccupied or over-thinking.

\section{Describing}

The model teacher guided the students to complete their first group assignment, namely arranging random letters into the word 'police officer'. The teacher approached every group, but only paid greater attention to groups that asked questions or found difficulties along the way. The students had demonstrated good interactions with the model teacher. The representatives of the groups, such as Mikayla-Kayleen and Jordan-Jonatan, were willing to stand up and voluntarily describe questions raised by the teacher. The conversations in these groups had been going well and they had successfully described their work result. The result of the observation showed that there were only two students who were able to exhibit calm, self-controlled, and confident attitudes in learning with the theme 'Occupations'. These students, namely
Mikayla and Kayleen, were considered to demonstrate outstanding progress.

The model teacher was able to boost the students' group working activities so that the students could help their own group members or even other groups' members. The teacher guided the students to always be active in developing the six aspects of child development and helped each group to have more varied participation. The learning activities occurring in the classroom were recorded in table 3.

Table 3. Sharing-Tasks Learning Activities

\begin{tabular}{ccc}
\hline No & Student's Name & Sharing task \\
\hline Group 1 & Kiyomi & MB \\
1 & Kimberlee & BSH \\
\hline 2 & & \\
Group 2 & Jordan & BSH \\
1 & Clara & BSH \\
2 & Jonathan & BSH \\
3 & Khenzo & BSH \\
\hline Group 3 & Katelina & BSH \\
1 & & \\
2 & Mikayla & BSB \\
\hline Group 4 & Timothy & MB \\
1 & & \\
2 & Siti & MB3 \\
\hline Group 5 & Kayleen & BSB2 \\
1 & & \\
2 & Emelin & BSH \\
\hline Group 6 & Jonathan & BSH8
\end{tabular}

Notes:

$\mathrm{MB}=$ early progress, $\mathrm{BSH}=$ expected progress $\mathrm{BSB}=$ outstanding progress

\section{Discussion}

Collaborative learning (CL) is an educational approach to teaching and learning that involves groups of students who work together to solve problems, complete tasks, or create products. In the CL approach, students are challenged both socially and emotionally when they listen to different perspectives, and are asked to articulate and defend their ideas. Thus, students begin to create their own unique conceptual framework and do not only rely on expertise. Students have the opportunity to communicate with peers, present and defend ideas, exchange diverse ideas, question other conceptual questions, and be actively involved in group discussions (Laal, Marjan, \& Laal Mozhgan, 2012). 
Collaborative sharing-tasks learning implemented in this study has benefited all students from different levels of academic, including the high, medium, and low achievers (Cahyani, 2017). Problem-solving activity in sharing-tasks learning motivates students to think more broadly in finding diverse solutions. Based on the analysis performed in this study, it was found that in general, the students were able to finish the tasks to arrange letters into the correct word 'police officer' and to match pictures with the correct word 'police car' completely. However, only two children demonstrated outstanding progress, eight showed expected progress, and three children were in an early stage of progress.

Referring to the achievement standard, it can be concluded that $76.92 \%$ of children have performed well in the sharing-tasks activities. Thus, it can be said that collaborative sharingtasks learning can improve the effectiveness of children's learning outcomes where children are more motivated in completing the tasks given to them, and are able to collaborate with members of their respective groups. During the research activities, the teacher was also able to position herself as a facilitator. The teacher made several attempts to create a fun learning environment for children, so that children could freely collaborate with their peers. This is corroborated with the results of the research by Gokhale (1995) who state that learning environment has a positive impact on student collaboration. In addition, Milanese, et al. (2010) also conclude that task sharing activity can influence the way tasks are accomplished in a social context.

The results of the research showed that the students from Santo Yoseph preschool helped one another to complete their assignments. Knowledge sharing is an important process in creating a competitive advantage. Environmental and organizational factors also influence the effective transfer of knowledge (Matzler \& Mueller 2011). Have found sharing a task is useful for identifying groupings of tasks simultaneously. In addition, Marhamah et al (2017) also showed that the experimental students' achieve- ment and collaboration had improved after they did sharing tasks and jumping tasks in the classroom. Therefore, it can be said that collaborative learning based on lesson study learning community (LSLC) may have a positive impact on student learning outcomes.

Research by Gifford \& Arvin (2009) has shown that collaborative learning through heterogeneous groups can accelerate learning, as well as improve student performance and the entire group behaviors. The provision of complex problems can improve learning efficiency for each group member (Kirschner, Fred \& Paul, 2011). Students with high, medium, or low academic level experience epistemological obstacles in learning. Therefore, collaborative learning is needed to facilitate all students to learn effectively. Findings of the current study can be used as a reference in creating a more effective learning in preschool classrooms. However, it needs to be recognized that the low-ability students were more likely passive and accepting towards the suggestions or input from friends with high academic ability.

\section{CONCLUSION}

Based on the results of the current study, it can be concluded that the implementation of colaborative sharing-tasks learning on the 'Occupations' topic at Santo Yoseph Preschool Group B1 in Ternate was highly effective. This is indicated by the degree of completeness achieved by the students. The students could perform the sharing-tasks activity well and establish collaboration between them. The high-ability children or students were willing to help other children with low academic ability (mutual learning). Collaborative sharing-tasks learning could improve the ability of the preschool students in understandding the 'Occupations' material. This study has not yet discussed the feasibility of the collaborative sharing-tasks approach for other themes in early childhood education. Further research needs to be conducted to address the topic.

\section{REFERENCES}

Asari, S. (2017). Sharing and jumping task in collaborative teaching and learning process. Didakti$k a, 23(2), 184-188$.

Cahyani, M. D. (2017). Pembelajaran kolaboratif sharing task dan jumping task pada topik rumus empiris dan rumus molekul berdasarkan ham- 
batan belajar siswa dan refleksi diri guru. Retreived from: https:/www.semanticscholar. org/paper/pembelajaran-kolaboratif-sharingtas-dan-jumping-Cahyani/f3fec2f2893 5a77663a034694ac7aad0ba-8910df

Gustina, E., Sumar H., \& Asep S. (2018). Sharing and jumping based didactical design in collaborative learning on the topic of covalent bonding. Internasional Journal of Reaserch in Counselling and Education, 1(2), https:// www.researchgate.net/publication/326740472 Sharing and Jumping Based Didactical De sign In Collaborative Learning on the topic of_Covalent_Bonding

Gifford, M.C. \& Arvin, A. (2009). Sharing in teams of heterogeneous, collaborative learning agents. International Journal of Intelligent Systems, 24, 173- 200.

Gokhale, A. A. (1995). Collaborative learning enhances critical thinking. Journal of Technology Education. 7, 22-30.

Isjoni. (2006). Model pembelajaran yang efektif bagi pendidikan anak usia dini. Retreived from: www.isjoni.net/ web/content/view/44/4/-44kTembolok-Laman sejenis: 17 Oktober 2007.
Kirschner, F., Fred P. \& Paul A. K. (2011). Task complexity as a driver for collaborative learning. Retreived from: http://citeseerx.ist. psu.edu/viewdoc/download? doi=10.1.1.1027. $5111 \&$ rep $=$ rep $1 \&$ type $=$ pdf.

Laal, M. \& Laal M. (2012). Collaborative learning: what is it? Procedia - Social and Behavioral Sciences, 3, 491-495.

Milanese, N, \& Cristina I. S. R. (2010). Shared learning shapes human performance: Transfer effects in task sharing. Cognition, 15-22, doi: https://doi.org/10.1016/j.cognition.2010.03. 010

Matzler, K. \& Julia M. (2011). Antecedents of knowledge sharing examining the influence of learning and performance orientation. Journal of Economic Psychology, 32(3), 317-329, https://www.sciencedirect.com/science/article/ abs/pii/S0167487010001406

Marhamah, M. \& Melvina. (2017). Pengaruh model pembelajaran kolaboratif berbasis lesson study learning community (LSLC). Jurnal Ilmiah Mahasiswa (JIM) Pendidikan Fisika, 2(3), 277-282. 